\title{
PANDEMIA: \\ LECCIONES Y ESTRATEGIAS URBANAS
}

\section{PANDEMIC:}

LESSONS AND URBAN STRATEGIES

\author{
Alfonso Xavier Iracheta Cenecorta \\ El Colegio Mexiquense, A.C. \\ axic@cma.edu.mx
}

\begin{abstract}
Since the begining of 2020 the world has experienced the COVID19 catastrofic pandemic. This article analizes the pandemic's origin and magnitude in Latin America; it also proposes an explanation relating COVID-19 with social and environmental conditions within a context of global capitalism sistemic crisis. It includes some urban responses and main trends, as well as it proposes new urban strategies beyond the previous pandemic status quo.
\end{abstract}

Keywords: Pandemic, crisis, city, strategies.

\section{Resumen}

Desde el inicio de 2020, el mundo se sumió en una crisis catastrófica por la pandemia de COVID-19. Este texto analiza el origen y la magnitud de la pandemia en América Latina; propone una explicación, relacionando la pandemia con las condiciones sociales y ambientales en un contexto de crisis sistémica del capitalismo global. Retoma algunas respuestas aplicadas en ciudades y las tendencias que se avizoran y propone nuevas estrategias urbanas que vayan más allá del estatus quo anterior a la pandemia.

Palabras clave: Pandemia, crisis, ciudad, estrategias.

1 Este texto es una ampliación y actualización de otro publicado en la revista ACE. Architecture, City and Environment, 15 (43), 9512. DOl: http://dx.doi.org/10.5821/ ace.15.43.9512 con el título: "La ciudad que quisiéramos después de COVID-19". 


\section{Introducción}

Dificil recordar otro evento en la era moderna que haya puesto de cabeza a todo el mundo y afecte a prácticamente todos los seres humanos sin distinción de color de piel, raza, religión, afiliación política, ingreso o preferencia sexual.

La pandemia del coronavirus no es una crisis, sino una catástrofe, un golpe externo ${ }^{2}$ que será seguido no sólo de una recesión extraordinariamente severa, sino también de duras luchas redistributivas (Dorre, 2020: 121). Pero es también, una advertencia de lo que podríamos esperar como futuro; en un año ha generado graves cambios en casi todos los órdenes de la vida social, económica y política. Ha transformado nuestra forma de trabajar, de habitar, de relacionarnos socialmente y de vivir nuestras ciudades.

La pandemia ha generado más perplejidad e incertidumbre que cualquier cambio en la política internacional e incluso más que las grandes transformaciones en las telecomunicaciones con la emergencia de las redes sociales. En el ámbito latinoamericano, estas incertidumbres se agudizan no sólo por la vulnerabilidad en que se encuentra una gran parte de los habitantes, sino por ser la región del globo más afectada y porque las instituciones internacionales y los gobiernos nacionales y locales no han logrado garantizar certezas a su población a lo largo del primer año de esta crisis de salud.

En diversos momentos hubo advertencias sobre el riesgo real de una pandemia global y letal. Por ejemplo, el presidente George Bush (2020) en una reunión del National Institutes of Healt describió con mucho detalle lo que hoy se está viviendo y advirtió la urgencia de prevenir la pandemia y los riesgos de que se difundiera por el mundo en periodos muy cortos, que sería muy letal y que duraría un año o más. La pregun-

$\overline{2 \text { Dorre (2020) }}$ define este golpe externo como "un fenómeno que se origina por fuera de los mecanismos funcionales de la sociedad. Pero el trascurso y la expansión de la enfermedad, su atención médica, las políticas estatales de higiene y salud, están marcadas a fuego por la sociedad; es decir lo antes exógeno se ha convertido en endógeno" (p.127) ta es ¿qué ocurrió con esta advertencia? La realidad, que enfrenta el mundo y particularmente los ciudadanos estadounidenses - país con mayor letalidad por COVID-19-. es que poco o nada se hizo.

Como se argumenta en el texto de recomendaciones, elaborado por un conjunto de expertos de diversas instituciones académicas mexicanas:

La pandemia sigue activa en el ámbito global. En varios países en los que se había advertido una disminución en la transmisión, lo que auguraba el control de la epidemia, han surgido rebrotes que obligan a replantear estrategias y acciones. La evidencia científica sobre los diversos aspectos alrededor de la pandemia se genera con gran dinamismo, literalmente todos los días, pero persisten grandes interrogantes sobre aspectos clave para enfrentar la pandemia con base en los resultados (INSP, 2021: 7-8).

Por lo anterior, el objetivo de este artículo es enfocarse en algunas lecciones, que la pandemia ha dejado a las ciudades durante estos primeros 14 meses, intentando a la vez adelantar alguna explicación sobre las causas de la crisis y su vínculo con otras grandes crisis, tales como la de la desigualdad socio-espacial y la del ambiente.

Al reflexionar sobre las lecciones y las causas, delineo algunas tendencias de la crisis y su relación con el patrón social y espacial de nuestras ciudades. A partir de éstas, propongo nuevas estrategias para convivir con la pandemia, con el fin de reducir sus impactos y convertir la crisis en oportunidades para ofrecer nuevas ideas y propuestas para nuestras ciudades.

El texto se divide en cinco secciones breves. Inicio con un análisis del origen y la magnitud de la pandemia en el subcontinente latinoamericano. Enseguida, explico las relaciones de la pandemia con las condiciones sociales y ambientales en un contexto de crisis sistémica global. Rescato algunas respuestas particularmente aplicadas en ciudades para posteriormente elucubrar sobre las tendencias que se avizoran y ade- 
lantar nuevas estrategias necesarias, con el fin de dar un paso adelante y no regresar simplemente al status quo anterior a la pandemia. El texto cierra con algunas reflexiones que propician un debate más profundo sobre el significado e impactos de la crisis global en la que estamos sumidos.

\section{Origen y magnitud del problema}

\section{El origen de la pandemia}

Como anotamos en un texto anterior (Iracheta, 2020a), la pandemia del coronavirus se originó en una ciudad y se diseminó por la movilidad física de las personas. Se expandió debido a la globalización intensiva, que se caracteriza por el aumento de los viajes a nivel mundial y por el crecimiento del intercambio de mercancías (Dorre, 2020: 128).

Su contagio principalmente se extendió a espacios urbanos y entre las razones de su aceleramiento destacan la cercanía y la interacción física entre personas, que facilitan la transmisión del virus.

Una de las características de la vida urbana es el contacto cotidiano y constante entre las personas, desde el saludo cortés con las manos o con besos en las mejillas hasta el contacto cercano entre parejas, familiares, amigos e incluso clientes. Prácticamente todas las actividades económicas y sociales de las personas en las ciudades implican este tipo de contactos.

De acuerdo con la información diariamente difundida por los medios de comunicación y especialmente por las redes sociales, la diseminación del virus se debió también al contacto físico indirecto, que se produce por la permanencia temporal del virus en diversos tipos de superficies. De ahí que estar en contacto con objetos y superficies contaminados con este virus puede transmitirlo.

Si a estas condiciones se agrega el concepto de densidad de población en las ciudades -en general, se define como el promedio de habitantes por hectárea aplicado en toda el área urbana o en sus barrios y particularmente asociado a las condiciones de pobreza y desigualdad-, se evidencia un creciente riesgo de contagio de la enfermedad.

Más específicamente, los riesgos de contagio se multiplican, debido a las aglomeraciones de personas que se transportan masivamente en sistemas de transporte públicos para abastecerse en mercados o centros comerciales o participar en espectáculos masivos artísticos, culturales, deportivos y eventos religiosos, políticos, sociales.

Ejemplos dolorosos son reportados por los medios masivos de comunicación y las redes sociales, que informan sobre el disparo de los contagios y fallecimientos en varios países debido al incremento en la movilidad urbana e interurbana de millones de personas por periodos de vacaciones, fiestas cívicas y religiosas o grandes eventos públicos.

\section{Algunos datos sobre América Latina}

En la tabla 1 se presentan datos en dos momentos (junio 2020 y enero 2021), que muestran la evolución de los casos confirmados y los fallecimientos por Covid-19. Su indicador es por cada 100 mil habitantes, a fin de hacer una correlación entre países latinoamericanos. No obstante, se mencionan más adelante las limitaciones de comparación.

Datos reconocidos por instancias internacionales evidencian un crecimiento exponencial del contagio y de fallecimientos en varios países entre los primeros meses de la pandemia (junio) y el inicio de 2021 (enero) (Johns Hopkins University, 2020).

Al atender los datos de la tabla 1 se observan comportamientos muy desiguales entre los países de la región latinoamericana. Los países con el mayor número de fallecimientos por cada 100 mil habitantes en el primer mes (junio 2020) son, en orden descendente: Perú (27.94), Chile (27.06), Brasil (26.72), Ecuador (25.79) y México (20.43). Para el segundo mes (enero 2021), Perú se mantuvo con el indicador más alto, seguido de Panamá (121.22), México (118.56), Argentina (105.24), Brasil (103.61) y Colombia 
(103.48), mientras que Chile (95.75) y Ecuador (85.59) han tenido un comportamiento menos letal. Los casos de Argentina y Colombia sorprenden, ya que en junio de 2020 tuvieron respectivamente 2.66 y 5.61 muertes y en enero de 2021 se multiplicaron por casi 40 veces en la primera nación y cerca de 19 veces en la segunda.

Por el contrario, los países con valores menores de fallecimientos en junio del 2020 son: Venezuela (0.14), Costa Rica (0.24), Cuba (0.75), Haití (0.88) y El Salvador (2.07). Para enero del 2021, Cuba (1.71), Haití (2.18) y Venezuela (3.98) mantuvieron muy bajo su indicador, mientras que Costa Rica (50.37) y El Salvador (24.31) multiplicaron por casi 12 veces el primero y por cerca de 210 veces el segundo con relación al dato de junio 2020.

El mayor número de los casos confirmados de contagio y de fallecimientos ha ocurrido en las áreas urbanas, destacando las grandes ciudades y convirtiendo a las metrópolis en epicentros del fenómeno. Como afirma Ricardo Méndez (2020):

desde hace décadas, las grandes ciudades mundiales han reforzado su función como centros de poder, actividad, gestión e interconexión del sistema global. También son espacios de máxima complejidad, que concentran lo mejor y lo peor de nuestras sociedades, lo que las convierte en exponente de múltiples formas de desigualdad. A diferencia de otras epidemias recientes, que mostraron unas pautas de localización muy distintas, la situación actual les añade un nuevo protagonismo al concentrarse en ellas los mayores impactos de la enfermedad. De este modo, las grandes áreas urbanas actúan como territorios de concentración del mayor volumen de contagios $y$, a la vez, como principales focos de propagación (Reyes et al., 2013). Puede afirmarse, por tanto, que si bien la Covid-19 ha alcanzado el rango de pandemia mundial, se trata, sobre todo, de un problema urbano y, más aún, metropolitano (47).

Aunque la información disponible con una desagregación espacial, capaz de sus- tentar investigaciones a esta escala, es escasa y muy heterogénea. El peso relativo máximo de las grandes metrópolis, al ser las principales puertas de acceso del virus, ha ocurrido en etapas tempranas y suele moderarse a medida que el virus se difunde a otras áreas del país (Méndez, 2020).

La megalópolis Boston-Washington concentraba a inicios de mayo de 2020 el 53\% del 1.13 millones de contagiados en el país, reduciéndose a mediados de julio a $27 \%$ de los 3.78 millones de infectados. En el mismo sentido, los estados de São Paulo y Rio de Janeiro sumaban $44 \%$ de todos los contagios en Brasil a comienzos de mayo de 2020 , reduciéndose a $26 \%$ dos meses y medio después. Por su parte, el área urbana Lima-Callao del Perú representó $72 \%$ y 56\% en esas mismas fechas y la Ciudad de México y el Estado de México $40 \%$ y $32 \%$ respectivamente. En Argentina, tanto la ciudad de Buenos Aires como la provincia de Buenos Aires concentraron $72 \%$ y $54 \%$ respectivamente. La única anomalía destacable es la región metropolitana de Santiago de Chile, donde los contagios incrementaron del $45 \%$ al 74\% (Méndez, 2020), lo que podría explicarse por la excesiva concentración poblacional y económica de la región frente al país.

En estas metrópolis se han evidenciado con mayor crudeza las limitaciones de las políticas sanitarias y urbanas, así como las limitaciones sociales para atender los llamados gubernamentales para reducir los riesgos de contagio, ya que la localización y la accesibilidad a las instalaciones hospitalarias no son adecuadas desde la óptica de una estrategia espacial acorde al tamaño de población y a su localización.

El Instituto Nacional de Salud Pública (INSP) (2021: 47) recomienda al Gobierno Federal Mexicano que considere comparar los casos nacionales de contagiados y fallecimientos por coronavirus con los internaciones, debido a su complejidad (47). El número de casos entre países depende de circunstancias diversas: desde la información producida por cada país hasta las diferencias demográficas y la incidencia de en- 
fermedades crónicas; así como la cobertura y calidad de sus sistemas de salud, sus capacidades para la vigilancia epidemiológica y para la generación y confiabilidad de sus estadísticas de mortalidad y morbilidad. A pesar de que se ajusten sus datos por tamaño de población, la metodología utilizada, la aplicación de pruebas de PCR, el conocimiento de los espacios y subgrupos de la población en los que se aplicaron tales pruebas y el uso de criterios clínicos en los casos sin confirmación de contagio insiden en los cálculos. Por estas razones, los juicios sumarios sobre el desempeño de países, regiones o ciudades son aún prematuros y de poca utilidad.

No existen dudas que los casos se han subestimado en todo el mundo. Sin embargo, la aplicación de pruebas serológicas sobre la presencia de anticuerpos contra la pandemia, aun cuando también subestime el número de casos, representa una mayor aproximación al número real de personas contagiadas.

Otro elemento a considerar es que los sistemas de notificación de fallecimientos por Covid-19 están sujetos a un conjunto de imponderables que no son necesariamente notificadas, tales como las muertes que ocurren en los hogares o en clínicas privadas. Por ello, la información oficial de los países no es necesariamente confiable y confirma la hipótesis de la subestimación.

Tabla 1

\section{Variación de casos confirmados y muertes por Covid-19 en países de ALC junio de 2020-enero de 2021}

\begin{tabular}{|c|c|c|c|c|c|c|c|c|c|c|}
\hline \multicolumn{5}{|c|}{ junio de 2020} & \multicolumn{4}{|c|}{ enero de 2021} & \multirow{2}{*}{$\begin{array}{l}\text { Aumento } \\
\text { de casos } \\
\text { de junio } \\
\text { de } 2020 \text { a } \\
\text { enero de } \\
2021\end{array}$} & \multirow{2}{*}{$\begin{array}{l}\text { Aumento } \\
\text { de muertes } \\
\text { de junio } \\
\text { de } 2020 \text { a } \\
\text { enero de } \\
2021\end{array}$} \\
\hline País & $\begin{array}{c}\text { Casos } \\
\text { confirmados }\end{array}$ & Muertes & $\%$ & $\begin{array}{c}\text { Muertes } \\
\times \text { cada } \\
100 \text { mil } \\
\text { habitantes }\end{array}$ & Casos & Muertes & $\%$ & $\begin{array}{c}\text { Muertes x } \\
\text { cada } 100 \\
\text { mil } \\
\text { habitantes }\end{array}$ & & \\
\hline Brasil & $1,274,974$ & 55,961 & 0.04 & 26.72 & $8,844,577$ & 217,037 & 2.5 & 103.61 & $7,569,603$ & 161,076 \\
\hline Perú & 272,364 & 8,939 & 0.03 & 27.94 & $1,093,938$ & 39,608 & 3.6 & 123.82 & 821,574 & 30,669 \\
\hline Chile & 263,360 & 5,068 & 0.02 & 27.06 & 699,110 & 17,933 & 2.6 & 95.75 & 435,750 & 12,865 \\
\hline México & 208,392 & 25,779 & 0.12 & 20.43 & $1,763,219$ & 149,614 & 8.5 & 118.56 & $1,554,827$ & 123,835 \\
\hline Ecuador & 53,856 & 4,406 & 0.08 & 25.79 & 241,292 & 14,623 & 6.1 & 85.59 & 187,436 & 10,217 \\
\hline Colombia & 80,811 & 2,786 & 0.03 & 5.61 & $2,015,485$ & 51,374 & 2.5 & 103.48 & $1,934,674$ & 48,588 \\
\hline Argentina & 55,343 & 1,184 & 0.02 & 2.66 & $1,867,223$ & 46,827 & 2.5 & 105.24 & $1,811,880$ & 45,643 \\
\hline $\begin{array}{l}\text { República } \\
\text { Dominicana }\end{array}$ & 29,764 & 712 & 0.02 & 6.7 & 203,946 & 2,513 & 1.2 & 23.82 & 174,182 & 1,80 \\
\hline Panamá & 29,905 & 575 & 1.90 & 13.77 & 311,244 & 5,063 & 1.6 & 121.22 & 281,339 & 4,488 \\
\hline Bolivia & 29,423 & 934 & 0.03 & 8.23 & 201,037 & 9,985 & 5.0 & 87.95 & 171,614 & 9,05 \\
\hline Guatemala & 15,828 & 672 & 0.04 & 3.9 & 154,212 & 5,465 & 3.5 & 31.69 & 138,384 & 4,793 \\
\hline Honduras & 15,994 & 471 & 0.03 & 4.91 & 140,929 & 3,447 & 2.4 & 35.95 & 124,935 & 2,976 \\
\hline El Salvador & 5,517 & 133 & 0.02 & 2.07 & 53,218 & 1,561 & 2.9 & 24.31 & 47,701 & 1,428 \\
\hline Haití & 5,722 & 98 & 0.02 & 0.88 & 11,181 & 243 & $2,2 \%$ & 2.18 & 54,59 & 145 \\
\hline Cuba & 2,325 & 85 & 0.04 & 0.75 & 21,261 & 194 & 0.9 & 1.71 & 18,936 & 109 \\
\hline Venezuela & 4,779 & 41 & 0.01 & 0.14 & 123,709 & 1,148 & 0.9 & 3.98 & 118,930 & 1,107 \\
\hline Costa Rica & 2,836 & 12 & 0.00 & 0.24 & 189,308 & 2,518 & 1.3 & 50.37 & 186,472 & 2,506 \\
\hline
\end{tabular}

Fuente: Johns Hopkins University (2021). 
La incertidumbre en los datos y las diferencias de políticas aplicadas por cada país exigen un análisis en profundidad de cada política nacional y urbana que incluya los contextos sobre morbilidad y sobre las condiciones socio-económicas y sanitarias de sus ciudades y sus barrios, a fin de entender un poco mejor las causas de estos comportamientos tan diferenciados.

Por ejemplo, destacamos el caso mexicano. Mauricio Mendoza señala que, mediante estudios realizados, "se ha demostrado la mayor concentración de patologías complejas y de exceso de mortalidad en los lugares o grupos donde prevalecen elevados niveles de marginación y exclusión social" (2020: 136).

En el mismo sentido, de acuerdo con Sosa et al. (2020: 2), debemos agregar los padecimientos de las personas contagiadas (datos de junio 2020) -las cifras indican que $20.09 \%$ padecía hipertensión, 19.52\% diabetes, $16.44 \%$ obesidad y $7.7 \%$ tabaquismo-, a la desigualdad social y las malas condiciones ambientales. De las comorbilidades asociadas a los fallecimientos por Covid-19 resaltan los siguientes porcentajes: 41.92\% padecía hipertensión, 36.87\% diabetes, $24.93 \%$ obesidad y $8.73 \%$ tabaquismo. Además, México es uno de los mayores consumidores de bebidas azucaradas y comida chatarra en el mundo.

Desde una perspectiva global, Saydah y Lochner (2010) señalan que el nivel educativo y la pertenencia a una familia con un ingreso por debajo de la línea de pobreza están asociados a un mayor nivel de mortalidad por diabetes. Igualmente Tang, Chen y Krewsky (2003) encontraron que la prevalencia de diabetes en ambos géneros se incrementa conforme disminuyen el ingreso y el nivel educativo.

Por ello, organizaciones sociales (\#CambiemosHábitos y \#PorUnMexicoSano) se preguntan ¿de quién es la culpa de tantos fallecimientos? La información desplegada hasta ahora sugiere que la gravedad y el agudizamiento de la pandemia están asociados también a estos factores de morbilidad y comorbilidad.

\section{Un intento de explicación}

La incertidumbre en todos los ámbitos de la vida social ha evidenciado que la pandemia ha creado nuevos problemas, influyó y visibilizó los problemas estructurales viejos al hacerlos vigentes y más urgentes. En efecto, es un mal público global que ha evidenciado la vulnerabilidad sistémica de la sociedad y que se asocia a múltiples factores destacando la emergencia climática que enfrenta el mundo y la desigualdad social.

Algo que parece incuestionable es la covergencia en la pandemia de una crisis sanitaria y otra ecológica. Para Sanahuja (2020), el patrón de origen zoonótico, que tiene la mayoría de los patógenos conocidos, evidencia la importancia de la interacción humana con los animales y, por ende, con sus ecosistemas. Tres factores influyen primordialmente en ese patrón de origen. El primero es la actividad humana, que causa la desintegración de ecosistemas a un ritmo cataclísmico. El otro factor es la existencia de una virusfera gigantesca, con un gran número de organismos patógenos parasitarios. El tercero es la creciente tendencia de esos organismos a buscar nuevos anfitriones donde alojarse, siendo los seres humanos los candidatos obvios, dado su número y omnipresencia (32).

Las crisis santaria y ecológica derivan del abuso de la naturaleza en niveles de no retorno, como claramente lo muestran los datos de la CEPAL (Bárcena et al., 2021). Si bien tales crisis exigen acciones colectivas y cooperación internacional, las respuestas en la práctica han sido muy diferentes. En la crisis sanitaria hay un sentido de urgencia y decisión política y en la climática persiste la indecisión y no existe un sentido de urgencia (Samaniego, 2021: 6). También, las acciones en la pandemia se basan en el conocimiento científico y la crisis climática es minimizada y se anteponen intereses políticos y económicos.

El resultado probable es el surgimiento de nuevas crisis sanitarias. Conforme las condiciones ambientales se agudicen, América Latina y el Caribe se enfrentan a una 
doble desigualdad, ya que son altamente vulnerables a los efectos del cambio climático, pese a su baja contribución (8.3\%) a las emisiones de efecto invernadero (Bárcena et al., 2020: 34 [gráfico 3]). Por ello,

el efecto sobre la salud local es grave superando varias veces las normas de salud (...) (y, en las ciudades) el estilo de desarrollo urbano ha estado acompañado de una mayor demanda de transporte, servicios públicos, insumos y productos y, en general, de una mayor presión sobre los recursos naturales y los bienes y servicios ambientales (Samaniego, 2021: 10).

La mayor parte de los países de la región se caracteriza por tener sistemas de salud débiles y no garantizar el acceso universal. Una de las causas de estos sistemas débiles es el gasto público promedio de los gobiernos centrales en el sector. Por ejemplo, tal gasto en 2018 se situaba en un 2.2\% del PIB regional, muy lejos del 6\% recomendado por la Organización Panamericana de la Salud (OPS) para reducir las inequidades y aumentar la protección financiera en el marco del acceso y la cobertura universal. Como consecuencia, la participación en planes de salud en Latinoamérica apenas alcanzaba el $57.3 \%$ (2016) y la cobertura con servicios de salud para la población situada en el decil de menor ingreso sólo atendía al 34.2\% (CEPAL, 2020b).

Por tanto, la salud es relevante para el desarrollo económico y el bienestar, tema que ha sido ampliamente estudiado (Adams et al., 2003; Haas, 2008; Dowd, Zajacova y Aiello, 2009; Cherlin, 2018; Currie y Goodman, 2020; Sosa, 2020: 4). Los grandes perdedores son los asentamientos humanos de bajo ingreso, que están ubicados en las periferias urbanas y su tenencia de la tierra es informal. Su vulnerabilidad se debe a la ausencia de servicios de salud en su entorno, las malas condiciones de la vivienda y el espacio público y la limitada accesibilidad a los servicios existentes, sea por lejanía y/o por insuficiencias en los sistemas de transporte (INSP, 2021).

De manera particular, el contagio de en- fermedades virales y su relación con factores socioeconómicos han sido analizados antes de la pandemia de Covid-19. Dijmărescu (2015) y Amin, Raja y Abro (2018) examinaron el vínculo entre variables sociales y económicas y la epidemiología del virus Hepatitis B y C. Por su parte, Mokhtar y Abd (2017) y Mohidem et al. (2018) indagaron sobre los determinantes sociales del contagio de la tuberculosis en Malasia. En estos estudios se corrobora que las variables socioeconómicas son determinantes para el contagio de enfermedades virales. Algunos de los factores que destacan son el ingreso económico, el nivel de educación/instrucción, las características de la vivienda y condiciones del espacio (rural/urbano).

Desde el enfoque del Índice de Pobreza Multidimensional, Barraza et al. (2020) identifican las condiciones preexistentes de pobreza que inciden en el nivel de riesgo de los hogares durante la pandemia en El Salvador. Los autores consideran estas condiciones: el acceso a servicios públicos clave (agua potable y saneamiento), el acceso a servicios de salud y de seguridad social, el hacinamiento en la vivienda y la persistencia del subempleo. Los resultados indican que más del $85 \%$ de la población de El Salvador sufre al menos un tipo de carencia. Esta situación vuelve vulnerables a los salvadoreños al exponerlos a mayores riesgos y los coloca en desventaja frente a crisis sanitarias, como la de Covid-19.

En el mismo sentido, Sosa et al. coinciden en que:

la relación que existe entre la disponibilidad a servicios básicos y el número de muertes y contagios por COVID19 es evidente (...) las dos variables que más inciden en el número de contagios son: falta de acceso a drenaje y no disponibilidad de agua entubada de la red pública. Ambos factores dejan de manifiesto que la falta de condiciones sanitarias básicas incrementa la exposición a enfermedades, especialmente, aquellas de tipo viral como el COVID19. En cuanto al número de muertes, las dos variables que tienen una mayor relación son: falta de acceso a drenaje y no disponibi- 
lidad de electricidad, ambas variables reflejan carencias estructurales que impiden a la población asegurar su bienestar, inhibiendo sus oportunidades de desarrollo (2020: 13).

En efecto, los individuos más afectados son quienes padecen pobreza y han sido socialmente excluidos. Ciertos tipos de empleo y condiciones habitacionales han sido determinantes para mantener el ingreso, la salud y la calidad de vida durante la cuarentena. Mientras que los trabajadores de cuello blanco (asalariados con un mínimo de estudios que realizan tareas semi-profesionales o profesionales de oficina, administración y coordinación de ventas) han podido sobrevivir por el teletrabajo (Home office), la mayor parte de los trabajadores de cuello azul (trabajadores que requieren trabajo manual en fábricas y talleres) o han perdido su empleo o están permanentemente en riesgo de contagio en sus espacios laborales.

En sociedades donde predomina la precariedad laboral y los empleados cuentan con prestaciones de salud limitadas y condiciones habitacionales magras, como es el caso de buena parte de América Latina, las crisis como la pandemia tienden a realimentarse. Esto en la crisis sanitaria ha provocado el crecimiento acelarado de los contagios, que ha causado el colapso de los sistemas de salud. Tal colapso ha provocado el aumento de fallecimientos.

Lo anterior agudiza a los problemas de la economía y de las relaciones sociales, que se traducen en el exacerbamiento de las diferencias políticas, reduciendo aún más las ya limitadas capacidades de respuesta de los gobiernos. La pandemia provoca igualmente la ruptura -temporal- de las relaciones sociales y la desconfianza a la cercanía con los "otros". Esto produce la reducción de las posibilidades del diálogo y la convivencia en las comunidades, en los asentamientos y en los barrios. Ha convertido al miedo en un sentimiento generalizado.

La crisis encuentra un mundo con muy baja capacidad de respuesta que se evidencia no sólo por tener sistemas de salud frágiles con acceso inequitativo entre cla- ses sociales como se ha referido, sino por la tendencia, en muchos casos, a la mercantilización de la salud y a la alta dependencia del exterior de los medios necesarios para enfrentar la pandemia: desde respiradores, hasta mascarillas y vacunas como resultado de las políticas neoliberales impuestas a nivel global (Sanahuja, 2020: 28).

\section{Como Boff acusa:}

El contexto del virus, casi nunca citado por los analistas de las redes de comunicación, es el sistema capitalista anti-naturaleza y anti-vida. Él hizo que el virus perdiese su hábitat y avanzase sobre nosotros. Este sistema de producción y de consumo asalta despiadadamente la naturaleza, saquea sus bienes y servicios y destruye el equilibrio de la Tierra (2021).

Estos posicionamientos "ponen el dedo en la llaga” y coincinden con reflexiones y argumentos explicativos desarrollados en los últimos años que concluyen que Esto no da para más (frase que es tomada para titular al libro de la Fundación Friedrich Ebert, 2020). Es decir, el modelo de vida predominante se ha vuelto insostenible, porque ha roto con los equilibrios básicos de la naturaleza por la explotación ilimitada de sus recursos y por la contaminación del aire que respiramos para vivir, del agua y del suelo que requerimos para alimentarnos, ingredientes que maximizan la pandemia.

La esencia de este modelo es hacer dogmas del crecimiento económico infinito y de la acumulación de la riqueza sin límite. Se ha hecho creer que la ciencia y la tecnología son competentes para resolver cualquier problema, que los seres humanos pueden continuar consumiendo y luchando por consumir cada día más y que todas las soluciones planteadas para enfrentar los estragos del cambio climático, la desigualdad social y espacial y la pobreza no afectarán la estructura del modelo en cuestión.

En otras palabras, la creencia casi religiosa de que el capitalismo, como es hoy, es la solución se ha llevado a límites, en algunos casos sin retorno. Las evidencias de la crisis ambiental, la persistencia de la pobreza y la 
ampliación de las brechas de la desigualdad entre grupos sociales y entre territorios evidencian lo contrario.

En los barrios y asentamientos pobres de las ciudades latinoamericanas se han hecho evidentes que diariamente se enfrentan las paradojas de la desigualdad y la pobreza. ¿Qué ocurre cuando no se tienen las condiciones habitacionales, laborales y emocionales para quedarse en casa? Un primer requisito para quedarse en casa es tener una. Ésta debe ser habitable y suficiente para una familia, condición que generalmente no se cumple. Por ello, como acierta Carlos:

la crisis del nuevo coronavirus revela que el simple acto de quedarse en casa o tener acceso a los tratamientos en hospitales no está al alcance de todos, pues los derechos no son iguales, lo que visibiliza la existencia de unas periferias urbanas donde reside buena parte de los sin derecho a cuarentena (2020:12).

La pandemia ha provocado también otros fenómenos, como el incremento de la violencia intrafamiliar, consecuencia de la acumulación de tensión entre los miembros del núcleo familiar quienes no pueden salir, carecen de recursos suficientes y tienen que convivir, estudiando y/o trabajando en un mínimo espacio habitacional.

Para Leilani Farha, la vivienda es "la primera línea de defensa frente al coronavirus" (cit. en Rodríguez y Sugraynes, 2020). La vivienda debería ser el lugar prioritario frente a ésta y otras amenazas por venir. Su uso debería ser reducir los contagios, enfrentar confinamientos con dignidad y seguridad, con espacios suficientes y diferenciados para trabajar, y estudiar a distancia y para convivir sin riesgos. Con esto, se evidencia nuevamente y con mayor urgencia que queremos y requerimos otra política social habitacional en las ciudades latinoamericanas. En esta política debe prevalecer el derecho a la vivienda adecuada, por encima del negocio inmobiliario, esto último es frecuente en casi todos los países de la región en las últimas décadas (Iracheta Cenecorta, 2020b).
El modelo económico-político dominante y la ausencia de políticas redistributivas, gestionadas y aplicadas por los gobiernos en casi todos los países latinoamericanos, han tenido entre sus consecuencias socioeconómicas la explosión de la informalidad en la economía en condiciones precarias y sin derechos sociales.

Es difícil cumplir la estrategia de sana distancia, en particular entre los usuarios del transporte público que necesitan trasladarse para realizar sus diferentes actividades; entre los trabajadores informales que dependen de las ganancias diarias; y entre quienes salen a adquirir alimentos y otros consumibles. Este panorama nada alentador evidencia que el ingreso es importante para que la familia pueda alimentarse.

Quienes menos tienen han sido afectados principalmente, porque carecen de acceso a Internet y por tanto a la educación y al trabajo a distancia. Tampoco tienen los medios para comprar en línea y los espacios en casa para sustituir estas carencias (INSP, 2021).

Ante este panorama, estamos obligados a repensar mucho de lo que sabemos y creemos saber sobre el sistema económico-político que nos rige, porque en él radican las principales causas de la pandemia y sus consecuencias en el descenso de la calidad de vida de la mayor parte de la población de las ciudades y las zonas rurales que viven en la pobreza.

Debemos también proyectar otras estrategias que nos lleven a transformaciones de fondo: del mercado capitalista, de la política, del consumismo, hacia un respeto a la dignidad de las personas y al derecho de la naturaleza y hacia el replanteamientos de nuestra percepción de las ciudades y de la vida urbana como la conocemos.

Después de 14 meses de iniciada la pandemia y de los análisis continuos de las políticas y medidas sanitarias en los países hechos por expertos y medios de comunicación, destacan otros factores responsables de un mayor o menor contagio que se deben considerar.

Por una parte, la laxitud contra el rigor y obligatoriedad de las medidas generalmen- 
te asumidas (el encierro en casa, la sana distancia, el uso del cubrebocas, el lavado frecuente de las manos, la desinfección de espacios, objetos y superficies) han sido claramente diferenciadas en los ámbitos nacionales y urbanos y han tenido resultados diferentes en la expansión del virus y en la mortalidad. Por ejemplo, la población argentina fue confinada obligatoriamente, Brasil no estableció medidas de control mayores, en México se recomendó que las medidas fueran sin obligación para la población y en Chile se adoptó una especie de toque de queda.

Otro factor fue el comportamiento social ante la pandemia, asociado a la estructura socioeconómica, al empleo, a la cultura y al cumplimiento de las recomendaciones o normas emitidas por los gobiernos. No existenten aparentemente estudios sobre esto. Por tanto, sólo es posible adelantar algunas elucubraciones, entre las que destacan por su impacto: el respeto al Estado de Derecho y a las normas oficiales y la (casi) inexistencia de empleo informal en las calles (por ejemplo, países de Asia y buena parte de Europa) frente a sociedades con menor respeto a las normas oficiales y a las recomendaciones para reducir el contagio y en las que persiste una alta proporción de empleo informal en las calles (por ejemplo, países de América Latina y el Caribe).

Si a estos factores se agregan las diferencias culturales sobre las formas, razones y magnitud de relaciones familiares y sociales, se observa una tendencia hacia la austeridad en muchos países europeos y asiáticos, manifestada por relaciones familiares esporádicas. En Latinoamérica, muchos países se caracterizan por relaciones muy frecuentes entre los miembros ampliados de las familias y por la cantidad de celebraciones públicas que congregan a un gran número de personas a lo largo del año - justamente, los contagios se elevaron después de estas celebraciones (Navidad, Año Nuevo y Semana Santa).

\section{Algunas respuestas}

Una vez que las posibilidades de contar con vacunas (durante el cierre del 2020) se hicieron más reales, las incertidumbres generadas por la pandemia no implican necesariamente la imposibilidad de solución o al menos la atenuación de la crisis.

Las respuestas a la pandemia globales y propiciadas por los organismos multilaterales -especialmente la Organización Mundial de la Salud (OMS)- se han traducido en acciones y estrategias escencialmente nacionales, impactando los equilibrios políticos entre gobiernos nacionales, regionales y locales, porque "la pandemia de COVID 19 ha planteado desafíos sin precedentes para la coordinación entre ámbitos de gobierno" (Navarro, 2020: 1).

Como propone Tosics (2020), mientras los Estados Naciones se han vuelto más fuertes al definir y controlar las políticas y acciones para enfrentar la pandemia, las ciudades y los gobiernos municipales se han encontrado en una situación peculiar y dificil. Por un lado, se han vuelto más subordinados a las administraciones y poderes nacionales. Por el otro, enfrentan nuevos niveles y formas de problemas sociales, económicos y espaciales, ante los que tienen qué reaccionar (2020: 1) y para los cuales no se contaba con experiencias o prácticas previas. En el mismo sentido, Barnet (2020) afirma que desde el punto de vista del poder, y a pesar del enorme esfuerzo que hacen los gobiernos locales en primera línea, los Estados-Naciones han recuperado notablemente su protagonismo en el tablero de juego global, al tiempo que el marco normativo, competencial y presupuestario local aún es precario, y las realidades metropolitanas débilmente reconocidas.

Por lo anterior, la mayor parte de las respuestas a Covid-19 ha sido experimental, de prueba y error, y permanentemente sujeta a la incertidumbre y al riesgo del fracaso. Por ello, se hacen presentes conceptos como cooperación, cohesión social, coordinación intergubernamental y gobernanza para afrontar esta emergencia. 
En este sentido, destacan las diferentes estrategias de confinamiento determinadas por cada ciudad con el propósito de reducir la expansión de los contagios. En un extremo, la implantación de virtuales toques de queda en ciudades europeas y asiáticas, frente a propuestas de responsabilidad compartida pero con libertad de movimiento en ciudades latinoamericanas como el caso de la Ciudad de México.

En todas las ciudades, la imposición de la "distancia social" entre las personas necesitó de la reorganización del espacio público, implicando la reducción del dominio del automóvil a fin de abrir espacio al peatón y a la bicicleta a través de la apertura de ciclovías emergentes o temporales en muchas ciudades.

Tosics menciona varios ejemplos europeos. El gobierno de Budapest clausuró temporalmente una margen del Río Danubio para uso de los ciclistas. El proyecto berlinés "calles para jugar" se orientó a recuperar espacios de calle para los niños - si al menos 7 residentes lo proponen, una calle se cierra al tráfico externo de vehículos y se abre para que los niños puedan salir a jugar en el arroyo vehicular. Milán amplió la red de banquetas y ciclovías en 35 kilómetros -el espacio para los vehículos de motor se disminuyó-; así como redujo el límite de velocidad a $30 \mathrm{~km} /$ hora. Con propuestas similares, Bruselas destinó todo el centro de la ciudad a los peatones y las bicicletas y redujo la velocidad vehicular a $20 \mathrm{~km} /$ hora, con estas propuesta se logra una distribución más equitativa del espacio para la movilidad (2020: 2-3).

En el mismo sentido, Bogotá definió una estrategia de movilidad conformada por 4 líneas de acción: limitar a 35\% como máximo la operación del transporte público; redefinición de horarios de transporte según los turnos laborales; 35 kilómetros de bicicarril o ciclovía y disminución de desplazamientos impulsando el teletrabajo (Rojas, 2020: 7).

Muchas otras intervenciones han surgido en las ciudades como respuestas inteligentes a la pandemia.
Las acciones de solidaridad en apoyo de quienes perdieron su empleo y para los más pobres, han redimensionado el tejido social en muchas ciudades, en particular en los niveles de barrio.

En otra dimensión y escala, han surgido acciones de gobiernos locales como en Bogotá (Rojas, 2020: 4), que definió un conjunto de estrategias y acciones estructuradas, denominado "Bogotá, Solidaridad en Casa", para enfrentar dos graves consecuencias de la pandemia: la reducción o pérdida del ingreso de muchas familias y el abastecimiento de alimentos. En el primer caso, destacan acciones como las transferencias monetarias y los bonos o ayudas en especie. En el segundo caso, se destacan estrategias públicas para garantizar el suministro de alimentos a través del mantenimiento de la cadena de abastecimiento, la aplicación de estrategias sanitarias en las plazas de mercado y la asociación con productores campesinos impulsando mercados móviles.

Desde la iniciativa privada, un ejemplo interesante es la campaña "Cocinamos México" (@cocinamosmexico) que se ha extendido a varias ciudades mexicanas. La campaña consiste en que las familias de un colectivo (padres de una escuela, club social) o individualmente preparan un número determinado de comidas en el hogar para luego entregarlas a la organización filantrópica que las distribuyen diariamente a grupos sociales necesitados.

Otro ejemplo relevante es la protección, desde la sociedad y/o los gobiernos locales, a los ancianos, por ejemplo Bilbao (Tosics, 2020). En muchos casos, les proveen de alimentos diariamente, mantienen vigilancia y cuidado de su salud y de apoyo para actividades que la pandemia no les permite realizar (hacer pagos, adquirir productos, etcétera), apoyos que se extienden a personas con discapacidades.

Otros casos son los comedores comunitarios, dirigidos específicamente a grupos afectados por la pandemia y la aportación de insumos, canastas o despensas de alimentos por las empresas industriales y los comercios - estos insumos pueden ser en- 
tregados directamente a familias o a organizaciones creadas para su reparto cotidiano.

En vivienda, se han establecido programas para subsidiar costos, tales como impuestos y derechos que los ciudadanos deben cubrir. Se han extendido las redes de telecomunicaciones y se ha aportado equipos a bajo costo o a fondo perdido para hacer efectiva la educación en línea y el teletrabajo (home office). Se han postergado los pagos de servicios evitando cortes en los hogares.

Los ejemplos recolectados por Eurocities o por School at Home Platform en Europa (Tosics, 2020: 2) sobre la educación en casa evidencian la capacidad para rediseñar los procesos pedagógicos, dar acceso a herramientas digitales y mejorar poco a poco los servicios educativos en línea.

Un tema central durante la pandemia ha sido el acceso a servicios alimentarios fuera del hogar, debido al cierre de restaurantes y lugares comerciales de venta de alimentos en muchas ciudades por largos periodos. La reconversión de muchos restaurantes para ofrecer comida para llevar y entrega a domicilio y el surgimiento de miles de opciones de comida preparada por no restauranteros - en muchos casos en los hogares - ha dado un giro importante a esta industria.

Conforme la sociedad urbana se va acostumbrando a nuevas formas de vida impuestas por la pandemia y se empieza avizorar una luz al final del túnel con la aprobación de diversas vacunas por los sistemas de salud nacionales, se plantea la posibilidad de evaluar respuestas como las arriba mencionadas para impulsar aquellas que podrían convertirse en permanentes y desincentivar aquellas que no debieran persistir.

\section{Tendencias y nuevas estrategias}

Si bien son inciertas las perspectivas para el presente y para el futuro próximo, deben considerarse, tomando como base la experiencia vivida durante los primeros $14 \mathrm{me}-$ ses de la pandemia de Covid-19, porque la persistencia de la crisis de salud ha evidenciado la existencia de acciones y estrategias que han mostrado sus bondades y eficacia. Por ello, tienden a ser adoptadas de manera creciente, y en algunos casos, se buscará que sean permanentes. Entre las acciones y las estrategias existentes destacan las siguientes:

- Solidaridad con quienes lo necesitan: alimentos, cuidados y otros apoyos cotidianos; peatonización y ciclovías: quitarle espacio al automóvil y revitalizar el transporte público; más espacio público: recuperando los existentes y creando o adaptando nuevos.

- Accesibilidad universal a las telecomunicaciones: ofreciendo a las viviendas y a las empresas pequeñan y micro acceso a Internet.

- Teletrabajo: ampliar las posibilidade de trabajar en casa, pero regulando la relación laboral y garantizando derechos y apoyos por el consumo de espacio, energía y redes.

- Teleeducación (educación en línea): facilitando a los maestros y a los padres de familia y alumnos los materiales y procesos pedagógicos en línea y definiendo hasta dónde se mantendrá la educación en casa y hasta dónde en el aula.

- Teleabasto y comercio: regulando y ofreciendo garantías y derechos a quienes asumen el reparto de bienes en los hogares.

En múltiples conversatorios en línea y en redes sociales se analizan las consecuencias y las perspectivas de la pandemia en la vida urbana principalmente. Existen indicios cada vez más claros sobre diversos temas, los cuales marcan las tendencias de procesos y cursos de acción, que más allá de la superación de la crisis de salud y económica, es probable que alcancen altos niveles de permanencia.

Entre otras razones, porque para muchas y muchos pensadores otra cara del duelo y la tragedia por la pérdida de millones de vidas humanas muestra que la naturaleza ha recibido, si bien momentáneo y limitado, un respiro al fin.

Igualmente, entre las grandes lecciones recibidas se percibe que la forma de vida en las ciudades puede recomponerse, a favor de la recuperación del tiempo y de la mejo- 
ra en la calidad de vida de muchos ciudadanos; del replanteamiento de lo que ha predominado como políticas urbanas, desde las de vivienda social, las de ordenamiento urbano, las de gestión del espacio público y las de la movilidad de personas y de vehículos, entre otras.

$Y$ esto provoca reflexiones sobre el significado de luchar por no regresar a la normalidad anterior a febrero de 2020, aunque se logre que la vacunación a nivel global sea exitosa y la humanidad salga de esta crisis, sino profundizar en las buenas prácticas observadas y convertirlas en cambios permanentes que impacten positivamente el futuro de las personas y de sus espacios, sean ciudades o lugares rurales.

Entre las tendencias más relevantes destacan varias por su impacto en la vida cotidiana de muchas personas y por sus consecuencias positivas en el desarrollo y funcionamiento de las ciudades. Convertir estas tendencias en propuestas y nuevas estrategias es una oportunidad que no se debe dejar pasar.

\section{El impacto del teletrabajo y la teleeducación en la vivienda}

\section{Trabajo en casa}

Para quien realiza teletrabajo, se ha invertido el tiempo diario que se vive dentro y fuera de casa. Los adultos del núcleo familiar que trabajan, dedican un mínimo de 8 horas entre traslado y trabajo o hasta 12 horas cuando las distancias o los tiempos de viaje entre hogar y empleo son grandes, como ocurre en buena parte de las ciudades. Por su parte, la jefa o jefe de hogar dedicado sólo al cuidado y al abasto requiere al menos entre 2 y 4 horas por día para llevar y traer a los niños de la escuela y para hacer las compras y trámites cotidianos.

Aunque estos datos pueden variar sensiblemente por grupos sociales y por ubicación dentro de la ciudad, los sectores de menor ingreso enfrentan con mayor crudeza su vida diaria al tener condiciones de hacinamiento en la vivienda y depender de transportes públicos fracturados y de mala calidad que tienden a alargar los tiempos fuera de casa.

Desde la óptica económica, el trabajo en casa evidencia el proceso de globalización de los mercados por las posibilidades reales de laborar desde cualquier lugar del planeta para cualquier organización o empresa independientemente de su localización física (Lerdo de Tejada, 2021).

La tecnología digital de asistencia, coordinación y control administrativo del trabajo en oficinas de cualquier naturaleza tenderá a dejar sin empleo a grandes cantidades de oficinistas. Desde la organización de archivos, la realización de trámites y transacciones bancarias o comerciales, el dictado y elaboracion de textos, la coordinación de grupos de trabajo y el control de avances de tareas requerirán menos personas y mejor tecnología digital.

Elementos que se han de considerar son el control de la información y la protección de datos, los cuales se han vuelto mucho más relevantes, porque al tiempo que las empresas, las oficinas públicas y las organizaciones sociales se adentran en el trabajo en casa, los riesgos de manejo inadecuado de datos, el robo de información, la suplantación de personalidad y sobre todo la tendencia al control social por medio de la concentración y centralización de los datos sensibles de las personas -incluyendo el reconocimiento biométrico- estarán a la alza.

El impacto en los distritos de oficinas podrá ser importante conforme crezcan los empleos en línea y se requiera menos espacio de oficina con la consecuente reducción de costos de renta y operación, aunque parcialmente se trasladarán a los trabajadores si no se regula el teletrabajo desde una perspectiva de derecho laboral. Una estrategia a considerar es el escalonamiento de los horarios de trabajo para reducir el número de trabajadores que concurren al mismo tiempo y para ampliar el espacio físico entre ellos.

Otra tendencia corresponde a los cambios de residencia de funcionarios y empleados de cuello blanco con posibilidades de cambiarse a lugares con menos riesgos 
de contagio y menos congestionados que los distritos de negocios y oficinas y más baratos que el suelo y las rentas dentro de la ciudad consolidada, como son las localidades semirurales o rurales. Una consecuencia no deseada será la tendencia al crecimiento del área urbanizada de las ciudades y su mayor dispersión y, consecuentemente, menor sustentabilidad desde la óptica del ambiente y del desarrollo urbano consolidado.

\section{Educación en casa}

En promedio un estudiante dedica 6 a 8 horas por día, se incluyen los tiempos de traslado desde y de vuelta a casa y en la escuela. La educación en línea parece que llegó para quedarse, por lo menos en los niveles de formación profesional, posgrado y capacitación para el trabajo, y probablemente menos en los niveles básicos y medio superior, en los que el contacto social y la relación directa entre docentes y alumnos es más necesaria.

Como empieza a probarse en muchos países, la tendencia probablemente se consolidará como un sistema híbrido, presencial y en línea. Esto implicará para el sistema educativo, adoptar nuevos enfoques y herramientas para los alumnos y los padres de familia, nuevas reglas de trabajo y la revisión y actualización de los derechos laborales de los maestros y el desarrollo de plataformas digitales que faciliten el trabajo y mejoren el aprendizaje.

Por lo anterior, la vivienda deberá repensarse, ya que el tiempo que el núcleo familiar dedicaba a la educación presencial, al trabajo en oficina y al abasto en tiendas se reducirá; así como el dedicado a las relaciones sociales, tales como visitas familiares, de amigos $\mathrm{o}$ al entretenimiento, comer fuera, ir al cine, tenderá a realizarse en casa.

Estas tendencias implican la necesidad de que se realicen nuevos diseños de vivienda, se implemente tecnología de comunicación de última generación y se lleve a cabo una revisión profunda del papel de las mujeres en el hogar, porque el trabajo de cuidados es realizado mayormente por mujeres en ciudades y el medio rural; por otro lado, el trabajo no remunerado ha implicado con la pandemia una sobrecarga para ellas al tener en casa a la familia y apoyar el proceso educativo de los hijos (RIMISP, 2021).

Si bien diversas estrategias de apoyo a la vivienda social han sido desarrolladas en diversos países y ciudades, extraña la falta de propuestas, especialmente gubernamentales, de ampliación de las viviendas para garantizar que cuenten con el espacio mínimo necesario para el teletrabajo, la teleeducación y el teleentrenimiento.

La oferta de créditos y apoyos para nuevas viviendas y para rediseñar, mejorar y/o ampliar las viviendas existentes, para que sus habitantes accedan a las plataformas tecnológica, al internet y a equipos de computación, requiere ser asumida por los fondos públicos para la vivienda, por las políticas habitacionales gubernamentales y por las empresas proveedoras de estos servicios.

Estas estrategias deberán considerar las perspectivas del trabajo y la educación en casa como tendencias que podrían convertirse en permanentes. También, como se comentó antes, requieren considerar el enfoque de género, porque las cargas de trabajo en el hogar han crecido con la pandemia y son mayoritariamente las mujeres quienes las han asumido, sumándolas a sus labores consideradas tradicionales, como es la atención y el cuidado del núcleo familiar.

En casos extremos de hacinamiento multigeneracional, es fundamental crear programas de confinamiento seguro fuera de la vivienda para evitar contagios masivos en los núcleos familiaries (Aravena et al., 2014: 57).

\section{El concepto ciudad deberá cambiar}

Como se mencionó, la densidad urbana tiene importantes implicaciones cuando se le asocia a la pandemia. Los debates sobre el desarrollo urbano a nivel global (UN-HABITAT, 2021) reconocen que la expansión urbana descontrolada, dispersa e insustentable, característica de las ciudades latinoameri- 
canas, requiere ser evaluada por los costos adicionales, que ha generado a los gobiernos locales para construir y mantener las infraestructuras urbanas y los que genera a la población que cada día requiere más recursos y tiempos de desplazamientos. Hay también que considerar los impactos negativos al medioambiente, porque el consumo de suelo y recursos naturales ha sido muy desproporcionado con relación a las necesidades reales de nuevo suelo urbano en cada ciudad (Iracheta Cenecorta, 2020b).

Han sugido propuestas orientadas al incremento de la densidad general de la ciudad y de la vivienda y frente a éstas. Surgen llamados de atención, a partir de una lección que está dejando la pandemia y que se refiere a la relación directa existente entre los niveles y riesgos de contagio y la densidad en las ciudades.

Como argumentan los expertos en salud pública, un camino para reducir los contagios es la necesaria desdensificación de los entornos que la gente no controla, como tiendas, escuelas restaurantes, clínicas, hospitales, hoteles, transportes, centros sociales (Aravena et al., 2014: 62), estrategia que si bien ha sido aplicada por la mayor parte de los países de la región no existe certeza si deberán continuar en el futuro. Lo que seguramente se mantendrá como política permanente es el establecimiento de máximos de aforo y densidad de personas en espacios públicos abiertos (estadios, conciertos, otros) y cerrados (iglesias, hoteles cines, otros), tomando como referente a las recomendaciones derivadas de la salud pública.

En el ámbito de los barrios urbanos y los asentamientos humanos de la periferia de las ciudades, particularmente los de bajo ingreso, es imperativo elaborar estrategias de regeneración urbana, a fin de hacerlos más autónomos en buena parte de las funciones, servicios y espacios públicos que requieren y en la oferta de bienes y servicios públicos y privados, a fin de reducir las necesidades de movilidad de sus residentes, mejorar su ingreso y generar menores impactos ambientales. En otras palabras, se debe recuperar el concepto de centralidad del barrio en la vida urbana y otorgarles la mayor prioridad en la planeación, las políticas y las inversiones públicas, para que sean los núcleos de la vida comunitaria en las ciudades.

En el contexto de los barrios y los asentamientos humanos en las ciudades, el espacio público adquiere una relevancia hasta ahora poco apreciada en muchas ciudades latinoamericanas. La gente seguirá saliendo, aunque en menor proporción, lo que implica menos vehículos en las calles y la tendencia al contacto social en espacios abiertos como parques, plazas y áreas verdes urbanas. Es necesario dedicar a estos espacios públicos, el mismo o mayor esfuerzo e interés gubernamental que el que históricamente se ha dado al sistema vial para automóviles.

Otros ejemplos claves son los mercados o plazas comerciales en las calles móviles o fijas, que en muchas ciudades han sido cerrados en lugar de regularlos y controlarlos, provocando que estas actividades económicas se trasladen a edificios en cada barrio - localidad que no cuentan espacialmente con las condiciones para el comercio minorista.

Desde las estrategias de la salud pública, en las ciudades destaca la urgencia de crear o actualizar sistemas comunitarios de salud a nivel de barrio o asentamiento humano, a fin de prevenir enfermedades y ofrecer atención primaria a la población, reduciendo la presión sobre los hospitales y los riesgos a los que se ve sometida una parte significativa de las personas que deben acudir a hospitales lejanos - que regularmente están sobresaturados - y tienen que realizar los traslados en vehículos públicos de baja confiabilidad.

Se debe ampliar la promoción de la salud hacia acciones salutogénicas, de cambio de comportamiento y empoderamiento, desarrollando redes a nivel comunitario, en localidades, comunidades y dentro de los centros de trabajo y de estudio (INSP, 2021: 55). Los especialistas en salud pública argumentan que la Atención Primaria para la Salud (APS) no es la puerta de entrada a la salud, sino el corazón del sistema, porque es en esta donde se dan los servicios de salud di- 
recta, próxima y efectivamente a las personas en sus comunidades, incluyendo la capacitación a las personas para que ejerzan un mayor control sobre los determinantes de su salud y así poder mejorarla (60-61).

La creación de sistemas comunitarios de cuidados a nivel de barrio y manzana o cuadra, a fin de atender y cuidar a la población de mayor edad y con discapacidades a través de instituciones públicas, sociales y privadas, reduciría la presión sobre los sistemas públicos de bienestar social y también la desigualdad social y espacial haciendo más incluyentes los servicios de salud y cuidados a la población vulnerable.

Con relación a la movilidad y accesibilidad, frente a un transporte poco confiable, se caminará y crecerá el uso de la bicicleta y otros vehículos no motorizados o mínimamente motorizados (scooter), por lo que la revaloración de las banquetas, veredas o aceras y las ciclovías o bicicarriles deberá tener prioridad, y por ello, deberán tener su propia infraestructura hecha ex professo para que se utilice como medio de transporte.

El transporte público deberá replantearse de manera que cada vehículo cuente con el espacio que la normatividad anti-Covid-19 exija en cuanto a distanciamiento entre asientos, ventilación, máximo de pasajeros y reparto de cubrebocas o mascarillas. Al mismo tiempo, es necesario incrementar el número de vehículos y corridas para reducir la densidad de pasajeros. Una consecuencia de dicha estrategia es el apoyo que desde los gobiernos se deberá dar a los transportistas para que puedan cumplirla.

En ciudades con altos niveles de desarroIlo, el transporte personalizado y automatizado crecerá y en ciudades de desarrollo medio y bajo, el transporte público y compartido se modernizará necesariamente, so pena de impulsar el uso de automóviles de uso particular.

Ejemplos ya operando en ciudades, son los sistemas de transporte modernizados y de mejor calidad, como el metro y el metrobús. Igualmente, el surgimiento de vehículos con conducción automática, tales como autobuses urbanos, trenes y metros sin con- ductores, tenderán a transformar cómo nos movemos dentro de las ciudades y a nivel interurbano.

\section{La formación profesional en plataformas digitales}

El crecimiento dinámico de las profesiones relacionadas con "lo digital" es una tendencia que se está acelerando en las universidades. El resto de las profesiones tendrán que especializarse en el manejo de plataformas digitales de todo tipo, porque buena parte de su trabajo será a distancia (Lerdo de Tejada, 2021).

En las Ciencias Básicas, muchas actividades de investigación, de laboratorio, de formación y de divulgación del conocimiento ya ocurren en línea y la tendencia es expansiva. En el área de la Salud, cada vez habrá más teleconsultas, teleanálisis de laboratorio e incluso varios tipos de telecirugías en medicina. Lo mismo ocurrirá seguramente en psicología. Documentos recientes sobre la pandemia recomiendan promover programas de consulta médica por teléfono o redes sociales, dirigidos por médicos generales o familiaries (INSP, 2021: 55).

En las Ciencias Sociales y Humanidades, crecerá el número de conversatorios, congresos y seminarios en línea, teleasesorías y consultorías en economía, finanzas y otras. Incluso, habrán los telejuicios en tribunales. Las Ciencias de la Comunicación han mostrado el camino y representan a las más adelantadas en digitalización y teletrabajo de todas las Ciencias Sociales.

En las Ingenierías y la Arquitectura, el telediseño y la teledirección e inspección de obras serán actividades crecientes e incluso la teleconstrucción mediante impresoras 3-D para ciertos edificios e infraestructuras.

En síntesis, una cantidad creciente de labores consideradas de gabinete o realizables a distancia en muchas profesiones tenderán a hacerse de manera digital, implicando cambios profundos en la educación universitaria y en la actualización y capacitación para que los profesionistas dominen estas tecnologías. 


\section{La producción de alimentos y el teleabasto}

\section{Producción de alimentos}

Como se adelantó antes, esta industria ya enfrenta cambios derivados de la pandemia. El temor a tener un sistema inmunológico débil tenderá a la búsqueda de más alimentos sanos y orgánicos y al crecimiento de la autoproducción de alimentos de patio y huertos urbanos, mientras no exista plena certeza en el inconsciente colectivo sobre la limpieza, valor nutricional y bajo riesgo de la alimentación fuera del hogar.

Esto tenderá a asociarse al ejercicio y deporte en casa (telegimnasio) y muy probablemente, a la expansión de la economía de la salud y la economía de los cuidados, especialmente para personas con dificultades para valerse solas: ancianos, discapacitados, niños.

\section{Teleabastecimiento y comercio}

Durante los primeros 14 meses de la pandemia se ha observado un crecimiento extraordinario de las empresas de mensajería. Éstas han logrado grandes avances en los procesos de automatización relacionados con la clasificación, distribución y entrega de todo tipo de mercancías, al grado de poder superar en relativamente poco tiempo algunas compras en tienda y superar la entrega de productos por mensajeros humanos trasladando estas labores a robots, drones y otros gadgets. Una evidencia es el crecimiento acelerado de empresas como Amazon, que se ha reportado sistemáticamente en los medios de comunicación masiva.

Un impacto no deseado de esto es el crecimiento exponencial de los residuos sólidos de embalaje y paquetería en buena parte de las ciudades.

Como ha sido analizado por organismos de ONU, como la CEPAL (2020a), o la banca internacional (BID, BM), los equilibrios entre los sectores de la economía se verán trasto- cados. Algunos van a crecer aceleradamente -química-farmacéutica, redes sociales, paquetería, entre otras- y otros serán sectores económicos en riesgo -entre los que destaca el turismo en general y una parte importante de su cadena de valor (transporte, hotelería y alimentos y entretenimiento). El turismo cultural y de negocios y reuniones enfrenta caídas más fuertes, porque buena parte de los espacios culturales con atractivo turístico se han cerrado y todos los eventos de negocios y otro tipo de reuniones que se realizaban en hoteles serán en línea (Lerdo de Tejada, 2021). Al igual que en el caso de las oficinas, es necesario imaginar qué usos se podrán dar a los espacios dedicados a funciones que por lo pronto se encuentran prácticamente detenidas.

\section{Para no concluir}

La emergencia sanitaria es la "punta del iceberg" de una crisis sistémica mundial, en la que la globalización acrecentó los riesgos y hoy enfrentamos una convergencia multiple de emergencias: sanitaria, económica, ambiental, de libertades personales, de cuidados (Álvaro Calix, FES-TSE). Otras catástrofes vendrán y podrán ser peores si no entendemos las enseñanzas de la pandemia. Atenuarlas en las ciudades es posible si rescatamos lo mejor de la vida comunitaria, del consumo sobrio, de la recuperación de la ciudadanía y de la regeneración de nuestras ciudades con la participación de los ciudadanos y sus organizaciones.

Más claro, es momento de repensar el concepto de ciudad global, porque, como Ziccardi acierta, para salir de esta crisis se necesita "construir colectivamente un nuevo pacto social y un patrón de gobernanza colaborativo y democrático que reivindique el derecho a la ciudad" (2020: 61).

Igualmente, porque la ciudad compacta y de gran tamaño se ha vuelto peligrosa ante un escenario de crisis ambiental o sanitaria. De ahí que retomar con más fuerza el policentrismo, sin regresar a modelos de urbanización dispersa, podría ayudar a reorganizar los sistemas urbanos nacionales, 
lo que podría implicar frenar o controlar las densidades, la fragmentación de los espacios habitacionales y las microviviendas y en particular, reducir el predominio del espacio contruido sobre los espacios libres, abiertos y verdes (Lois, 2020). En palabras de Florida (cit. en Corti, 2020), si bien la lógica económica de la innovación y el talento induce a la concentración, la preocupación por la salud y bienestar humano puede impulsar en cambio la desconcentración.

Desde lo social, la CEPAL (2020a) ha evidenciado que la pandemia ha expuesto los problemas estructurales del modelo económico y las fallas de los sistemas de protección social y los esquemas de atención a la salud en los países latinoamericanos, lo que se ha vuelto muy costoso para todos. Por ello, establece que debemos crear un nuevo Estado de Bienestar basado en un modelo social, orientado a reducir sensiblemente la pobreza y la desigualdad en la distribución de la riqueza; que garantice en las ciudades los principios y acciones del Derecho a la Ciudad y a la Vivienda Adecuada y que tome en cuenta las materias relacionadas de orden fiscal, social y de producción. Los gobiernos de las ciudades y los actores sociales necesitan actuar y a la vez deben responder la pregunta: ¿cómo pueden las ciudades ser al tiempo los sujetos y los lugares para esta transformación?

En su último reporte sobre las ciudades en el mundo, ONU-HABITAT (UN-Habitat por sus siglas en inglés) (2020), adelanta posibles respuestas aseverando que el valor social e intangible de la ciudad, a través de sus instituciones y organizaciones, es el factor central para enfrentar una crisis como la de Covid-19 y para controlar su diseminación. Este valor radica en la capacidad de la sociedad y del Estado para proveer bienestar de manera coordinada y corresponsable.

Sin embargo, como se argumenta a lo largo de este texto, varios temas han adquirido notoriedad y requieren ser atendidos con prioridad. Sin duda, destaca la construcción de sistemas comunitarios para la prevención y atención de la salud, el acceso al agua y a los alimentos, y todo ello debe ocurrir en espacios públicos y privados para vivir con dignidad.

Como concluyó la 1a. sesión de "Aprendizajes en Vivo" organizado por Ciudades y Gobiernos Locales Unidos (CGLU), Metrópolis y ONU-HABITAT, la vivienda adecuada es vital para contener la pandemia de Covid-19, porque sin ella el distanciamiento social y la higiene son simplemente imposibles.

Hacer de los barrios y del espacio público -abierto, verde- el centro del desarrollo urbano e impulsar las estrategias de movilidad sustentable es crucial para recuperar la vida social con mayor seguridad y menores riesgos.

Al mismo tiempo, se deben poner en valor los efectos positivos que ha generado el aislamiento y el distanciamiento social, como es el aceleramiento de las relaciones virtuales y la explosión de las tecnologías de comunicación, porque el teletrabajo, la teleeducación y en general, un conjunto de actividades sociales tenderán a ser atendidas en casa ofreciendo alternativas que hace sólo un año se avizoraban para un futuro más lejano.

¿Es razonable proponer que debemos alcanzar un justo medio o un equilibrio entre lo que podemos hacer en casa beneficiándonos como ciudadanos y beneficiando al ambiente, y lo que debemos realizar socialmente, mejorando el tejido y las relaciones comunitarias?

Nuevas políticas urbanas de ámbito local, como las sugeridas, deben ofrecer las condiciones y los incentivos necesarios para su realización. De manera que permitan emprender la transformación de las ciudades para que sean justas y funcionen para todos, repensando el concepto de ciudad y regenerando los modelos espaciales y las infraestructuras para que no degraden los recursos naturales y la biodiversidad y usando la Cuarta Revolución Industrial para crear un mundo que sea más incluyente, más verde y más limpio para favorecer a la humanidad y al ambiente. 


\section{Fuentes consultadas}

Adams, Peter, Michael Hurd, Daniel McFadden, Angela Merrill y Tiago Ribeiro (2003), "Healthy, Wealthy, and Wise? Tests for Direct Causal Paths between Health and Socioeconomic Status", Journal of econometrics, 112 (1), pp. 3-56.

Amir, Nasrullah, Wassem Raja y Mukhtiar Ahmed Abro (2018), "Burden of Hepatitis B And C Infection According to Socioeconomic Status, Annals of PIMS-Shaheed Zulfiqar Ali Bhutto Medical University, 14 (2), pp. 206-209.

Aravena, Susana; Arébalo, Martha; Bazoberry, Guillermo; Blanco, Claudia; Corrêa do Lago, Luciana; Estrada, Luis; Fernández, Raúl E.; Wagner, Alejandro Florian; Franco, Jorge; García Miranda, Karen; García Quispe, Ramiro; González, Gustavo; Guadamuz Madriz, Osman; Iracheta, Alfonso; Landaeta, Graciela; Miyashiro Tsukazan, Jaime; Morales, Raúl; Montenegro, Julio Mora; Morán, Amanda; Nahoum, Benjamín; Ortiz, Enrique; Raffo, Alberto; Rojas Ugalde, Adriana; Silveira Belato, Clara; Sugranyes, Ana; Trundle Fagoth, Luis Enrique (2014), La vivienda, entre el derecho y la mercancia; las formas de propiedad en América Latina, Montevideo, TRILCE-Centro Cooperativo Sueco.

Bárcena Ibarra, Alicia, José Luis Samaniego, Wilson Peres y José Eduardo Alatorre (2020). La emergencia del cambio climático en América Latina y el Caribe: ¿seguimos esperando la catástrofe o pasamos a la acción?, Santiago de Chile (Chile), Comisión Económica para América Latina y el Caribe (CEPAL).

Barnet, Oriol (2020), "Metrópolis y Covid-19, Café de las Ciudades, <https://bit. ly/2RrmOh5, abril 2020.

Barraza, Rodrigo; Barrientos, Rafael; Díaz, Xenia; Pleitez, Rafael y Tablas, Víctor (2020), Covid-19 y vulnerabilidad: una mirada desde la pobreza multidimensional en El Salvador, Programa de las Naciones Unidas para el Desarrollo de
América Latina y el Caribe, Serie de documentos de la política pública, < https://bit.ly/3wwArKu>, 11 de febrero de 2021.

Boff, Leonardo (2021), "Por fin descubrimos el planeta Tierra", Servicios koinonia, <https://bit.ly/3f1vPpR>, 13 de febrero de 2021.

Bush, George (2020), "Brut.Media", París, Brut, <https://bit.ly/3oAHSNX>, 13 de febrero de 2021.

Calix, Álvaro (2017), "El desafío de la transformación social-ecológica en América Latina", Nueva Sociedad, < https://bit. ly/2Rrl5bD >, abril 2017.

Carlos, Ana Fani Alessandri (2020), "As faces da desigualdade socioespacial iluminadas pela crise da covid-19", Ensaios, Instituto de Estudos Avançãdos da Universidade de São Paulo, <https:// bit.Iy/3bEDGaT>, 11 de febrero de 2021.

CEPAL (Comisión Económica para América Latina y el Caribe (2020a), Datos del Banco de Datos de Encuestas de Hogares BADEHOG), < https://bit.ly/3wtQF77>, 12 de mayo de 2020.

CEPAL (Comisión Económica para América Latina y el Caribe (2020b), El desafío social en tiempos del COVID-19, <https://bit.ly/3fthgKO>, 16 de febrero de 2021.

Cherlin, Andrew J. (2018), "Psychological Health and Socioeconomic Status among Non-Hispanic Whites, Proceeding of the National Academy of Sciences, 115 (28), pp. 7176-7178, doi: 10.1073/ pnas. 1808753115.

Corti, Marcelo (2020), "Coronavirus: dispersión y densidad urbana en debate", Café de las Ciudades, <https://bit. ly/3oPhPCX>, marzo 2020.

Currie, Janet y Goodman, Joshua (2020), "Parental Socioeconomical Status, Child Health, and Human Capital", en Steve Bradley y Colin Green (eds.), The Economics of Education, Londres, Academic Press, pp. 239-248. 
Dijmărescu, Irina (2015). "Economic and Social Factors Fighting against Hepatitis $B$ and C Contagion". Romanian Journal of Economics 40 (1), pp. 210-219.

Dorre, Klaus (2020), "La pandemia del coronavirus: una catástrofe global explosiva", Astrolabio Nueva Época: Revista digital del Centro de Investigaciones y Estudios sobre Cultura y Sociedad, núm. 25, Buenos Aires, CIECS (CONICET-UNC), pp. 119-145.

Dowd, Jennifer Beam, Anna Zajacova y Allison Aiello (2009). "Early Origins of Health Disparities: Burden of Infection, Health, and Socioeconomic Status in US Children", Social Science and Medicine, 68 (4), pp. 699-707, doi: 10.1016/j. socscimed.2008.12.010.

Farha, Leilani (2020), "Declaración, Relatora Especial sobre el derecho a una Vivienda Adecuada de la ONU" Ginebra (Suiza): Oficina del Alto Comisionado de Naciones Unidas de Derechos Humanos, <https://bit.ly/3fEOret>.

Friedrich Ebert Stiftung (2020), Esto no da para más. Hacia la transformación social-ecológica en América Latina, Ciudad de México (México), Fundación Friedrich Ebert Stiftung (proyecto regional: Transformación social-ecológica).

Hass, Steven. (2008). "Trajectories of Functional Health: the "Long Arm" of Childhood Health and Socioeconomic Factors". Social Science and Medice, 66 (4), pp. 849-861, doi: 10.1016/j.socscimed.2007.11.004.

INSP (Instituto Nacional de Salud Pública) (2021), "Nota conceptual y recomendaciones", Seminario virtual (Reflexiones sobre la respuesta de México ante la pandemia de COVID-19 y sugerencias para enfrentar los próximos retos), 23-27 noviembre de 2020, Ciudad de México.

Iracheta Cenecorta, Alfonso Xavier (2020a), "La ciudad que quisiéramos después de COVID-19", ACE: Architecture, City and Environment, 15 (43), doi: 10.5821/ ace.15.43.9512

Iracheta Cenecorta, Alfonso Xavier (2020b), Otra ciudad es posible: los retos del desarrollo urbano en América Latina, Ciudad de México (México), Proyecto Regional: Transformación Social-Ecológica en América Latina (TSE), Fundación Friedrich Ebert Stiftung (FES).

Johns Hopkins University (2020). "Mortality Analyses", Coronavirus Resource Center, <https://coronavirus.jhu.edu/ data/mortality $>$.

Lois González, Rubén C. (2020), "La ciudad y el urbanismo en tiempos de pandemia", Crítica Urbana, Revista de estudios urbanos y territoriales, 3 (15), Universidad de Santiago de Compostela, < https://bit.ly/3vrHzrL>.

Lerdo de Tejada, Jorge (2021), 10 predicciones más relevantes para el 2021, [YouTube], 28 de enero de 2021, <https:// bit.ly/3f4S4vb>, 31 de enero de 2021.

López Moreno, Eduardo R. (2021), "Covid y la utopia reinventada", El País, < https:// bit.ly/349VEOS>, 11 de abril de 2021.

Méndez, Ricardo (2020), Sitiados por la pandemia, del colapso a la reconstrucción: apuntes geográficos, Madrid (España), Editorial Revivies.

Mendoza, Mauricio (2020), "Rezago social y letalidad en México en el contexto de la pandemia de enfermedad por coronavirus (Covid-19): una aproximación desde la perspectiva de la salud colectiva en los ámbitos nacional, estatal y municipal", Notas de Población, núm.111, pp. 133-154.

Mohidem, Nur Adibah; Hashim, Zailina; Osman, Malina; Shaharudin, Rafiza; Muharam, Farrah Melissa; Makeswaran, Punitha (2018), "Demographic, Socioeconomic and Behavior as Risk Factors of Tuberculosis in Malaysia: A Systematic Review of the Literature", Reviews on Environmental Health, 33 (4), pp. 407-421. 
Mokhtar, Khairiah y Abd Rahman, Nur (2017), "Social determinants of tuberculosis contagion in Malaysia", Annals of Tropical Medicine and Public Health, 10 (5), Gale Academic OneFile, p. 1215.

Navarro, Alejandro (2020), "Divergencias en la coordinación intergubernamental para la gestión del Covid-19", en Carmen Medel Palma et al. (coords.), México ante el Covid-19: acciones y retos, Ciudad de México (México), Universidad Autónoma Metropolitana/Cámara de Diputados-Consejo Editorial H. Cámara de Diputados, pp. 205-214.

Reyes, Raquel, Roy Ahn, Katherine Thurber, Thomas F. Burke. (2013), "Urbanization and Infection Diseases: General Principles Historical Perspective and Contemporary Challenges", en: Urbanization and Infectious Diseases: General Principles, Historical Perspectives, and Contemporary Challenges, Nueva York (Estados Unidos), Springer, pp. 123148.

RIMISP (Centro Latinoamericano para el Desarrollo Rural) (2021), Los hogares encabezados por mujeres son más vulnerables a los efectos sociales de la pandemia, <https://bit.ly/3vhsN6B>, 28 de enero de 2021.

Rodríguez, Alfredo y Ana Sugraynes (2020), " "Quédate en casa" y el derecho a la vivienda", Crítica Urbana, Revista de Estudios Urbanos y Territoriales, 3 (12), <https://bit.ly/3bKmvEQ>, mayo 2020.

Rojas, María Fernanda (2020), Desafíos de la gestión urbana y de los servicios públicos - mitigación de la pandemia en las ciudades, Concejal de Bogotá, presentada en el 3er Foro Internacional de FLACMA y OPS/OMS: Desafíos de la Gestión Urbana y de los Servicios Públicos-Mitigación de la Pandemia en las Ciudades de LATAM, 8 de mayo de 2020.

Samaniego, José Luis (2021), "La emergencia del cambio climático en América Latina y el Caribe, ¿̇seguimos esperando la catástrofe o pasamos a la ac- ción?", ponencia presentada en la Cátedra Transformación Social Ecológica (TSE), Sesión 7: La emergencia del cambio climático en América Latina y el Caribe, 15 de marzo.

Sanahuja, José (2020), COVID-19: riesgo, pandemia y crisis de gobernanza global, Anuario CEIPAZ 2019-2020.

Saydah, Sharon y Lochner, Kimberly (2010), "Socioeconomic Status and Risk of Diabetes-Related Mortality in the US", Public Health Reports, 125 (3), pp. 377388.

Sosa, Miriam; Ortíz, Edgar; Cabello, Alejandro (2020), "Impacto del rezago social en el número de muertes y contagios por COVID-19 en México: análisis con redes neuronales artificiales empleando información a nivel municipal", Contaduría y administración, núm. 65, especial COVID-19, pp. 1-17.

Tang, Mei; Chen, Yue; Krewski, Daniel (2003), "Gender-Related Diferences in the Association between Socioeconomic Status and Self-Reported Diabetes", International Journal of Epidemiology, 32 (3), pp. 381-385.

Tosics, Ivan (2020), "Urban Lessons Learnt from the Pandemic", Cooperative City Magazine, <https://bit.ly/33XVVUp>, 1 de febrero de 2021.

UN-Habitat (2016), World Cities Report 2016, Urbanization and Development. Emerging Futures. Nairobi (Kenya), UN-Habitat, <https://bit.ly/3hKjSqs>, 27 de noviembre de 2020.

UN-Habitat (2020), World Cities Report 2020: The Value of Sustainable Urbanization, Nairobi (Kenya), United Nations Human Settlements Program.

Ziccardi, Alicia. (2020), "Las grandes regiones urbanas y el distanciamiento social impuesto por el Covid-19". Astrolabio, nueva época, Buenos Aires, CONICET. 
Recibido: 8 de febrero de 2021. Reenviado: 17 de febrero de 2021. Aprobado: 12 de abril de 2021.

\section{Alfonso Xavier Iracheta Cenecorta}

Doctor en Estudios Regionales por la Universidad de Varsovia. Actualmente, es Profesor-Investigador de El Colegio Mexiquense y Director General de Centro EURE. Miembro del Sistema Nacional de Investigadores, nivel II. Desarrolla las siguiente líneas de investigación: Estudios y Planeación del Desarrollo Urbano-Metropolitano, Suelo, Vivienda, principalmente. Sus últimas publicaciones son: Otra ciudad es posible Los retos del desarrollo urbano en América Latina, Ciudad de México, Friedrich-Ebert-Stiftung Proyecto Regional Transformación (2021); "Dilemas ambientales y gobernanza: la Gran ciudad de México" en Jacobi et al. (orgs.), Dilemas ambientais-urbanos em duas metrópoles Latino Americanas São Paulo e Cidade do México no século XXI, São Paulo, Paco Editorial, (2021); "La ciudad que quisiéramos después del COVID-19" en Revista Architecture, City and Environment, BarceIona, Universitat Politècnica de Catalunya (2020). 